\title{
New and Old Genes Associated with Topotecan Resistance Development in Ovarian Cancer Cell Lines
}

\author{
ANDRZEJ KLEJEWSKI ${ }^{1,2}$, MONIKA ŚWIERCZEWSKA ${ }^{3}$, KATARZYNA ZAORSKA $^{3}$, \\ MACIEJ BRĄZERT ${ }^{4}$, MICHAŁ NOWICKI ${ }^{3}$, MACIEJ ZABEL ${ }^{3,5}$ and RADOSŁAW JANUCHOWSKI ${ }^{3}$ \\ Departments of ${ }^{1}$ Nursing, ${ }^{2}$ Obstetrics and Womens Dieseases, and \\ ${ }^{3}$ Histology and Embryology, Poznan University of Medical Sciences, Poznan, Poland; \\ ${ }^{4}$ Division of Infertility and Reproductive Endocrinology, Department of Gynecology, \\ Obstetrics and Gynecological Oncology, Poznan University of Medical Sciences, Poznan, Poland; \\ ${ }^{5}$ Department of Histology and Embryology, Wrocław Medical University, Poznan, Poland
}

\begin{abstract}
Background: Low effectiveness of chemotherapy in ovarian cancer results from development of drug resistance. Topotecan is a drug used as second-line chemotherapy for this cancer type. We analyzed development of topotecan resistance in ovarian cancer cell lines. Materials and Methods: A chemosensitivity assay, MTT test, was performed to assess drug resistance. Quantitative polymerase chain reaction $(Q-P C R)$ assays were performed to determine $A B C B 1, A B C G 2, A L D H 1 A 1$, IFIH1, SAMD4 and EPHA3 gene expression. Results: We observed dose-dependent responses to topotecan. In all topotecan-resistant cell lines an overexpression of ABCG2, IFIHI and SAMD4 genes was observed. Expression of $A B C B 1$ gene was observed in one cell line. Expression of ALDH1Al was up-regulated in A2780 and down-regulated in SKOV-3-resistant cell lines. Short-time exposure led to similar patterns of gene expression for the investigated genes. Conclusion: Expression of $A B C G 2$ and $A B C B 1$ genes plays the most important role in topotecan resistance. The role of other investigated genes seems to be complementary.
\end{abstract}

Epithelial ovarian cancer is the most common cause of death from gynecological malignancies $(1,2)$. At the beginning of therapy ovarian cancer is chemosensitive in most cases, however during treatment most patients develop resistance

This article is freely accessible online.

Correspondence to: Andrzej Klejewski, Department of Nursing, Poznan University of Medical Sciences, Smoluchowskiego 11 St., 60-179, Poznan, Poland. Tel: +48618612267, e-mail: aklejewski@ump.edu.pl

Key Words: Ovarian cancer, topotecan resistance, drug transporters, new genes. to cytotoxic agents used in chemotherapy (3). The first line of chemotherapy includes taxane and platinum compounds $(4,5)$. However most patients with initially good response to this therapy eventually develop drug resistance. In the second line of chemotherapy in case of platinum/taxaneresistant patients other drugs like topotecan (TOP), doxorubicin (DOX) and gemcitabine are mainly used (5-7). Unfortunately only $15-35 \%$ of patients respond to drugs used in second line of chemotherapy.

Topotecan is semi-synthetic derivative of camptothecin, an alkaloid derived from extracts of the tree Camptotheca acuminate (8). This agent is an inhibitor of DNA topoisomerase I, a nuclear enzyme that regulates overwinding or under-winding of the DNA helix $(9,10)$. It stabilizes the enzyme-DNA complex that results in inhibiting DNA replication, and transcription and eventually results in cancer cell death (11). Unfortunately cancers can develop resistance to TOP. Many cancers develop mutations in topoisomerases or down-regulate their expression which makes these enzymes less sensitive to drug action (12). However, the most important mechanism responsible for TOP resistance is an active removal of this drug from cancer cells. The main protein responsible for active removal of TOP from cancer cells is BCRP (breast cancer resistant protein) encoded by $A B C G 2$ gene. Expression of this gene was reported among others in breast and ovarian cancer and cancer cell lines (13-17). In our previous study we observed that TOP resistance could be also related to expression of glycoprotein $\mathrm{P}$ (P-gp) encoded by $A B C B 1(M D R 1)$ gene $(16,18)$. Recently we reported the up-regulation of many collagen genes in TOPresistant ovarian cancer cell lines $(19,20)$.

Our microarray results indicated new genes that can be also associated with TOP resistance such as, EPHA3, IFIHI and SAMD4. EPHA3 is a member of a big family of receptor tyrosine kinases (RTKs). This family is composed 
of 16 members divided into group $\mathrm{A}$ and $\mathrm{B}$ on the basis of the type of ligands (ephrins) $(21,22)$. It is a component of Eph/ephrin tyrosine kinase system and plays an important role in tumor cells proliferation, angiogenesis and tumor progression (22-24). Increased expression of EPHA3 was reported in many cancers. In gastric cancer up-regulated expression of EPHA3 correlated with TNM, stage and poor prognosis (25). In colorectal and hepatocellular carcinoma increased expression of EPHA3 was correlated with tumor size, histological grade, TNM stage, as well as with metastasis (26) (27). Recently the role of EPHA3 in development of MDR in small cell lung cancer (SCLC) was reported (28).

IFIH1 encoded by melanoma differentiation-associated gene $5(M D A-5)$ is a cytosolic receptor and plays an essential role in the first line of defense against viral infection by sensing double-stranded RNA (29). After recognition of viral dsRNA IFIH1 activates signaling cascade resulting in expression of the type I IFNs and IFN-stimulated genes to initiate antiviral immune responses (30). It can also induce death of virus-infected cells by a mechanism involving DNA fragmentation (31). It has been reported that ectopic expression of IFIHI gene can induce death of cancer cells (32). However, the role of IFIH1 in drug resistance has not been so far described.

SAMD4 (sterile alpha motif domain containing 4A), also known as a SMAUG1, is a regulatory protein that regulates target mRNAs by binging to Smaug Recognition Elements (SREs) (33). It is involved in post-transcriptional regulation of genes expression by repression of translation and mRNA decay $(33,34)$. The best of our knowledge the role of this gene in drug resistance or cancer has not been described so far.

Recent results suggest that cancer stem cells (CSCs) are responsible for development of drug resistance after exposure on cytotoxic agents. These cells are characterized, among others, by high expression level of aldehyde dehydrogenase-1A1 (ALDH1A1) as well as high levels of expression of drug transporters like P-gp or BCRP (35). An increased number of ALDH1A1-positive cells was also reported in ovarian cancer and ovarian cancer cell lines and correlated with cisplatin (CIS), paclitaxel (PAC) and TOP resistance (36-38).

Most research concerning drug resistance development is conducted on pairs of drug-sensitive and -resistant cell lines, where cell lines are exposed to drug at least for a few months. Much less in known about the response of cancer cells to cytotoxic agents during the first days of treatment. The goals of our study were: (i) Compare the expression level of new and old genes involved in TOP resistance in TOP sensitive and resistant ovarian cancer cell lines, (ii) determine the expression of these genes during first days of exposure to TOP.

\section{Materials and Methods}

Reagents. TOP was obtained from Sigma (St. Louis, MO, USA). RPMI-1640, MEM and DMEM medium, fetal bovine serum, antibiotic-antimycotic solution, and L-glutamine were also purchased from Sigma (St. Louis, MO, USA). A Cell Proliferation Kit I (MTT) was purchased from Roche Diagnostics $\mathrm{GmbH}$ (Mannheim, Germany).

Cell lines and cell culture. In this study we used three ovarian cancer cell lines, the established ovarian cancer cell lines A2780 and SKOV-3 as well as the primary ovarian cancer cell line W1. The human ovarian carcinoma A2780 and SKOV-3 cell lines were purchased from ATCC. A2780 sublines that were resistant to TOP [A2780TR1 and A2780TR2 (A2780 topotecan resistant)] were generated by exposing A2780 cells to TOP at incrementally increasing concentrations. SKOV-3 sublines that were resistant to TOP [SKOV-3TR1 and SKOV-3TR2 (SKOV-3 topotecan resistant)] were generated by exposing SKOV-3 cells to TOP at incrementally increasing concentrations. The human primary ovarian cancer cell line W1 was established using ovarian cancer tissue obtained from an untreated patient. W1 subline resistant to TOP [W1TR (W1 topotecan resistant)] was obtained by exposing W1 cells to the TOP at incrementally increasing concentrations. The final concentration used for selecting the resistant cells was $24 \mathrm{ng} / \mathrm{ml}$ of TOP and were two-fold higher than the plasma concentrations of the TOP two hours after intravenous administration.

All of the cell lines were maintained as monolayers in complete medium [MEM medium (A2780), DMEM medium (SKOV-3) and RPMI-1640 medium (W1) supplemented with $10 \%$ (v/v) fetal bovine serum, 2 pM L-glutamine, penicillin (100 units $/ \mathrm{ml})$, streptomycin (100 units $/ \mathrm{ml})$ and amphotericin B $(25 \mu \mathrm{g} / \mathrm{ml})]$ at $37^{\circ} \mathrm{C}$ in a $5 \% \mathrm{CO}_{2}$ atmosphere.

Incubation of cells with TOP. In a time-course experiments, the W1, A2780 and SKOV-3 cell lines were treated with TOP at a concentration of $10 \mathrm{ng} / \mathrm{ml}$ and $20 \mathrm{ng} / \mathrm{ml}$ (W1, A2780) or $20 \mathrm{ng} / \mathrm{ml}$ and $50 \mathrm{ng} / \mathrm{ml}$ (SKOV-3). The starting cell concentration was $0.5 \times 10^{6}$ (W1 and A2780) or $0.2 \times 10^{6}$ (SKOV-3) in $1 \mathrm{ml}$ of medium per one well in 6 well plate. Cell count and viability were determined before the cells were used in the different assays. Viability was determined by the trypan blue exclusion criteria. 24,48 and $72 \mathrm{~h}$ after treatment cells were harvested and used for RNA isolation.

Drug sensitivity assay. The drug sensitivity of the SKOV-3 cell line and the TOP-resistant sublines were confirmed by an MTT cell survival assay. Briefly, all cell lines were seeded at a density of 3,000 cells/well in 96-well plates. The cells were allowed to grow for $48 \mathrm{~h}$ and subsequently treated with fresh medium supplemented with or without increasing concentrations of TOP and incubated for $72 \mathrm{~h}$ at $37^{\circ} \mathrm{C}$. After $72 \mathrm{~h}$ of exposure, $10 \mu \mathrm{l}$ of the MTT labelling reagent was added to the medium (the final concentration of MTT was $0.5 \mathrm{mg} / \mathrm{ml}$ ), and the cells were incubated for an additional $4 \mathrm{~h}$. Following this process, $100 \mu \mathrm{l}$ of solubilisation solution was added to each well. The absorbance of each sample was measured in a microplate reader at $570 \mathrm{~nm}$ with a reference wavelength of $720 \mathrm{~nm}$, according to the manufacturer's protocol. The negative control was conducted using cell-free culture medium containing both the MTT reagent and solubilisation solution. The experiments were repeated three times, and each concentration in a given experiment was tested 
Table I. Oligonucleotide sequences used for RQ-PCR analysis.

\begin{tabular}{|c|c|c|c|c|}
\hline Transcript & & Sequence (5'-3' direction) & ENST number & Product size \\
\hline \multirow[t]{2}{*}{ IFIHI } & $\mathrm{F}$ & GGGGCATGGAGAATAACTCA & 00000263642 & $132 \mathrm{bp}$ \\
\hline & $\mathrm{R}$ & TGCCCATGTTGCTGTTATGT & & \\
\hline \multirow[t]{2}{*}{ SMAD4 } & $\mathrm{F}$ & CCAAAGGTGCAAGACACAAA & 00000251091 & $146 \mathrm{bp}$ \\
\hline & $\mathrm{R}$ & CGGAGTCAGGATCATCTGGT & & \\
\hline \multirow[t]{2}{*}{ EPHA3 } & $\mathrm{F}$ & GTTCCTGCAATGCTGGCTA & 00000336596 & $104 \mathrm{bp}$ \\
\hline & $\mathrm{R}$ & CGGGCACTTAGCACACTTC & & \\
\hline \multirow[t]{2}{*}{$A B C G 2$} & $\mathrm{~F}$ & TTCGGCTTGCAACAACTATG & 00000237612 & $128 \mathrm{bp}$ \\
\hline & $\mathrm{R}$ & TCCAGACACACCACGGATAA & & \\
\hline \multirow[t]{2}{*}{$A B C B 1$} & $\mathrm{~F}$ & TGACAGCTACAGCACGGAAG & 00000265724 & $131 \mathrm{bp}$ \\
\hline & $\mathrm{R}$ & TCTTCACCTCCAGGCTCAGT & & \\
\hline \multirow[t]{2}{*}{$A L D H 1 A 1$} & $\mathrm{~F}$ & GTTGTCAAACCAGCAGAGCA & 00000165092 & $115 \mathrm{bp}$ \\
\hline & $\mathrm{R}$ & CTGTAGGCCCATAACCAGGA & & \\
\hline \multirow[t]{2}{*}{ GAPDH } & $\mathrm{F}$ & GAAGGTGAAGGTCGGAGTCA & 00000229239 & $199 \mathrm{bp}$ \\
\hline & $\mathrm{R}$ & GACAAGCTTCCCGTTCTCAG & & \\
\hline \multirow[t]{2}{*}{$\beta$-actin } & $\mathrm{F}$ & TCTGGCACCACACCTTCTAC & 00000331789 & $169 \mathrm{bp}$ \\
\hline & $\mathrm{R}$ & GATAGCACAGCCTGGATAGC & & \\
\hline \multirow[t]{2}{*}{ HPRT1 } & $\mathrm{F}$ & CTGAGGATTTGGAAAGGGTG & 00000298556 & $156 \mathrm{bp}$ \\
\hline & $\mathrm{R}$ & AATCCAGCAGGTCAGCAAAG & & \\
\hline \multirow[t]{2}{*}{$B 2 M$} & $\mathrm{~F}$ & CGCTACTCTCTCTTTCTGGC & 00000558401 & $133 \mathrm{bp}$ \\
\hline & $\mathrm{R}$ & ATGTCGGATGGATGAAACCC & & \\
\hline
\end{tabular}

in duplicates. Cell viability was expressed as a percentage of the untreated control (mean \pm SEM).

Examination of gene expression by quantitative polymerase chain reaction $Q-P C R$. Changes in $A B C G 2, A B C B 1, E P H A 3, I F I H 1, S A M D 4$, and $A L D H 1 A 1$ genes expression in the W1, A2780, SKOV-3 and TOPresistant cell lines were examined. RNA was isolated using the Gene Matrix Universal RNA purification Kit (EURx Ltd., Gdańsk, Poland), as described by the manufacturer's protocol. Reverse transcription was performed using the M-MLV reverse transcriptase (Invitrogen) as described in the manufacturer's protocol using a thermal cycler (Veriti 96 well Thermal Cycler). $2 \mu \mathrm{g}$ of RNA were used for cDNA synthesis. Real-time PCR was performed using the Applied Biosystems PCR System (7900HT Fast Real-Time PCR System), Maxima SYBR Green/ROX qPCR Master Mix (Thermo Fisher Scientific, Waltham, Massachusetts, USA) and sequence-specific primers, as indicated in Table I. Glyceraldehyde-3-phosphate dehydrogenase (GADPH), $\beta$-actin, hypoxanthine-guanine phosphoribosyltransferase 1 (HRPT1) and beta2-microglobulin $(\beta 2 M)$ served as the normalizing genes (geometric mean) against which changes in the examined genes expression were compared. Gene expression was analyzed using the relative quantification (RQ) method. RQ estimates the difference at the level of gene expression against a calibrator (RQ of the calibrator $=1$ ). The drug sensitive cell lines (W1, A2780, SKOV-3) were used as the calibrators. The analysis was conducted employing the standard formula: $\mathrm{RQ}=($ where for the sample (drug-resistant line) - for the calibrator (drug sensitive line)). The graphs were made using Sigma Plot.

For amplification $12.5 \mu \mathrm{L}$ of Maxima SYBR Green/ROX qPCR Master Mix (Fermentas), $1 \mu \mathrm{L}$ of each primer (Oligo, Warsaw, Poland) (Table I), $9.5 \mu \mathrm{l}$ of water, and $1 \mu \mathrm{l}$ of cDNA solution were mixed together. One RNA sample of each preparation was processed without RT-reaction to provide a negative control in subsequent PCR. Sample amplification included a hot start $\left(95^{\circ} \mathrm{C}, 15 \mathrm{~min}\right)$ followed by 45 cycles of denaturation at $95^{\circ} \mathrm{C}$ for $15 \mathrm{sec}$, annealing at $60^{\circ} \mathrm{C}$ for $30 \mathrm{sec}$, and extension at $72^{\circ} \mathrm{C}$ for $30 \mathrm{sec}$. After amplification Melt Curve analysis was performed to analyze product melting temperature. The amplification products were also resolved by $3 \%$ agarose gel electrophoresis and visualized by ethidium bromide staining.

Statistical analysis. The statistical analysis was performed using Microsoft Excel software. The statistical significance of the differences was determined by applying the Student's $t$-test.

\section{Results}

MTT analysis of the TOP-resistant and sensitive cell lines. The SKOV-3TR1 and SKOV-3TR2 TOP-resistant variant sublines of the SKOV-3 human ovarian cancer line were established by the stepwise selection of SKOV-3 cells cultured in growth media with increasing TOP concentration. In order to determine the sensitivity of the TOP-sensitive and TOP-resistant cell lines, the cells were treated with increasing concentrations of the TOP. We observed a concentrationdependent effect of TOP in the investigated cell lines (Figure 1) and statistically significant difference in the $\mathrm{IC}_{50}$ values between TOP sensitive and resistant cell lines (Table II). SKOV-3TR2 cell line was nearly four times more resistant than SKOV-3TR1 cell line. The TOP sensitivity of A2780 and W1 resistant sublines were determined previously $(16,18)$.

Gene expression analysis in TOP-resistant ovarian cancer cell lines

Analyses of $A B C G 2$ and $A B C B 1$ gene expression in $S K O V$ 3 TOP sensitive and -resistant cell lines. Previously we observed very high transcript levels of $A B C G 2(B C R P)$ in 


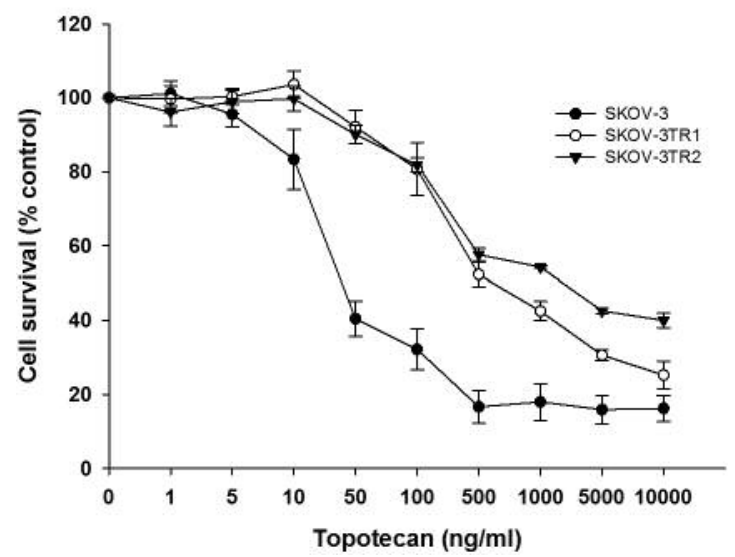

Figure 1. MTT cell survival assay. SKOV-3, SKOV-3TR1 and SKOV$3 T R 2$ cells were seeded at density of $3 \times 10^{3}$ cells/well in 96-well plates and treated with or without increasing concentration of TOP, at $37^{\circ} \mathrm{C}$ for $72 \mathrm{~h}$, and viability of cells was determined. The experiments were repeated at least three times, and each concentration was tested in duplicate in each experiment. Viability was expressed as a percent of an untreated control (mean \pm SEM).

Table II. Summary of cell lines resistance to topotecan treatment.

\begin{tabular}{lc}
\hline Cell line & $\mathrm{IC}_{50}(\mathrm{ng} / \mathrm{ml})$ \\
\hline SKOV-3 & $44.6(29.7-68.7)$ \\
& 1 \\
SKOV-3TR1 & $631(447-816)$ \\
& $14 \uparrow *$ \\
SKOV-3TR2 & $2464(2,358-2,563)$ \\
& $55 \uparrow * *$
\end{tabular}

$\mathrm{IC}_{50}$ mean is indicated for topotecan. The drug resistance in SKOV-3 cell line was assigned as 1 . Underline values indicate multiplicities of resistance with respect to SKOV-3 cell line. ${ }^{*} p<0.05,{ }^{* *} p<0.001$.

TOP-resistant variants of A2780 and W1 cell lines $(16,18)$. To determine whether the TOP-resistance in SKOV-3 sublines is also associated with $A B C G 2$ overexpression, expression of the $A B C G 2$ mRNA was assessed. We observed a statistically significant increase of $A B C G 2$ transcript in both TOP-resistant cell lines $(p<0.01$ in SKOV-3TR1 cell line and $p<0.001$ in SKOV-3TR2 cell line). However, we observed differences of $A B C G 2$ mRNA level in both TOP-resistant cell lines. Seven-fold higher transcript level of ABCG2 was observed in the SKOV3TR2 cells, and expression in the SKOV-3TR1 cells increased about two hundred-fold (Figure 2A). SKOV3TR2 cell lines was also characterized by statistically significant increase of $A B C B 1$ gene expression $(p<0.01)$ (Figure 2B).
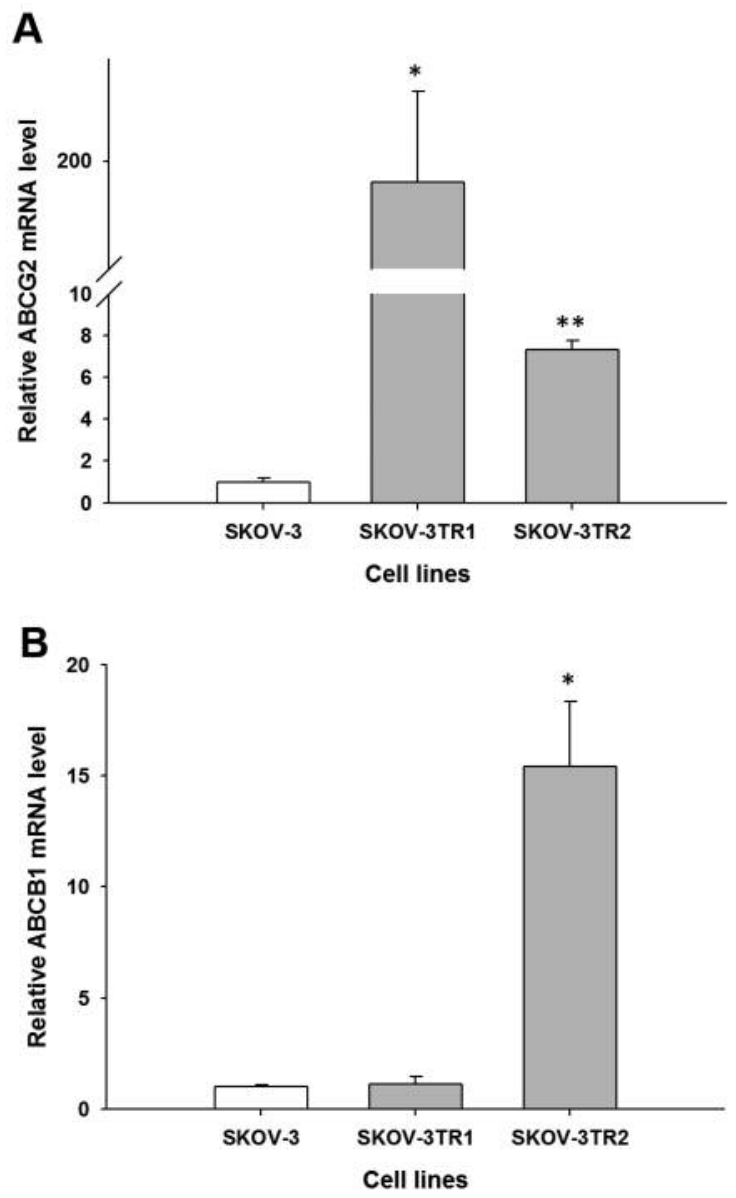

Figure 2. Expression analysis (Q-PCR) of ABCG2 (A) and $A B C B 1(B)$ genes in SKOV-3 and TOP-resistant sublines. The Figure presents relative gene expression in resistant cell lines (grey bars) with respect to the SKOV-3 cell line (white bars) assigned as 1. The values were considered significant at $* p<0.01$ and $* * p<0.001$.

Analyses of new genes expression in TOP-resistant ovarian cancer cell lines. The role of $A B C G 2$ and $A B C B 1$ in TOP resistance is well documented. However, our microarray data (not shown) suggest that other genes like: IFIHI, SAMD4 and EPHA3 can also be involved in TOP resistance. The gene expression levels of IFIH1, SAMD4 and EPHA3 were examined to determine whether the TOP-resistance in our cell lines is associated with the increased expression of these genes. We observed statistically significant increase of IFIHI transcript level in W1TR cell line $(p<0.01)$ (Figure $3 \mathrm{~A})$, both A2780 TOP-resistant cell lines $(p<0.001$ in A2780TR1 cell line and $p<0.05$ in A2780TR 2 cell line) (Figure 3B) and both SKOV-3 TOP-resistant cell lines $(p<0.01)$ (Figure $3 C)$. The transcript level of $S A M D 4$ was significantly increased in W1 TOP-resistant cell line $(p<0.05)$ (Figure 4A), both A2780 

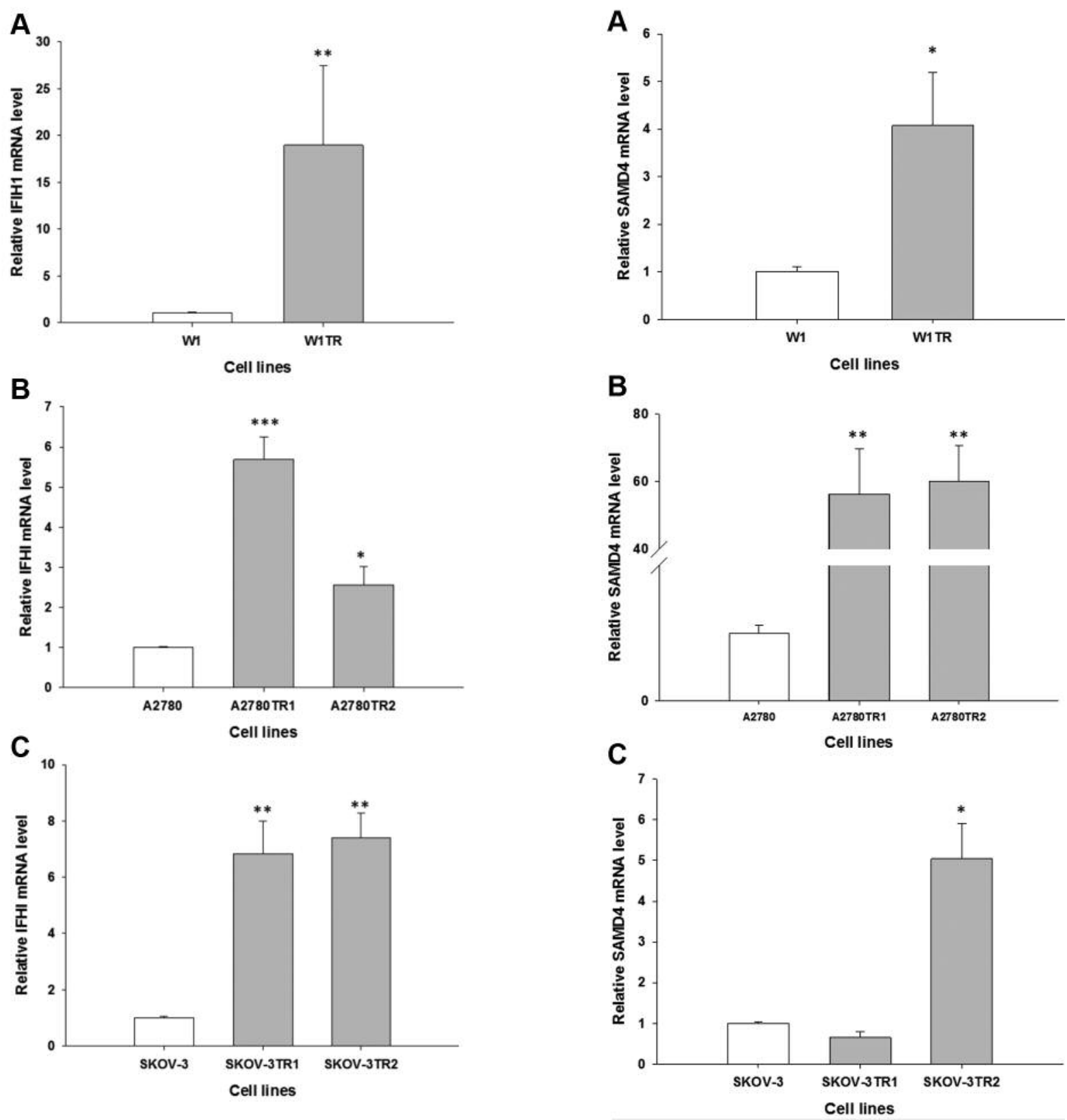

Figure 3. Expression analysis (Q-PCR) of IFIH1 gene in W1 (A), A2780 (B), SKOV-3 (C) and TOP-resistant sublines. The Figure presents relative gene expression in resistant cell lines (grey bars) with respect to the sensitive cell line (white bars) assigned as 1 . The values were considered significant at $* p<0.05, * * p<0.01$ and $* * * p<0.001$.

TOP-resistant cell lines $(p<0.01)$ (Figure 4B) and in SKOV3 TR2 cell line $(p<0.05)$ (Figure 4C). However, in A2780 TOP-resistant cell lines we observed about ten-fold higher level of SAMD4 mRNA than in others TOP-resistant cell lines. We observed an enormous increase in expression of EPHA3 gene - over a 1,000-fold in W1TR cell line $(p<0.01)$

(Figure 5). In contrast, we did not observe changes in EPHA3 mRNA level in other TOP-resistance cell lines (not shown). Analyses of ALDHIAl gene expression in TOP-resistant ovarian cancer cell lines. Our previous data indicated that TOP resistance is associated with increased expression of CSCs marker ALDH1A1 in W1TR cell line (38). To check 
whether this is also true in other TOP-resistance cell lines we checked mRNA level of ALDHIAl in TOP-resistant A2780 and SKOV-3 sublines. We observed some increase in ALDH1Al transcript level in both A2780 TOP-resistant sublines, although statistically significant increase was observed only in A2780TR2 cell line $(p<0.05)$, (Figure 6A). In contrast, in both SKOV-3 TOP-resistant sublines we observed a decrease in ALDH1Al mRNA level $(p<0.05$ in SKOV-3TR1 and $p=0.055$ in SKOV-3TR2) (Figure 6B).

Early response to TOP-treatment in ovarian cancer cell lines. In the second part of our research we wanted to check if the same genes can be involved in early response to TOP treatment. In these experiments ovarian cancer cell lines were treated with low concentration of TOP (W1 and A2780 - $10 \mathrm{ng} / \mathrm{ml}$ and $20 \mathrm{ng} / \mathrm{ml}$; SKOV-3 - $20 \mathrm{ng} / \mathrm{ml}$ and $50 \mathrm{ng} / \mathrm{ml}$ ). Gene expression was investigated after 24,48 and $72 \mathrm{~h}$.

Analyses of $A B C G 2$ and $A B C B 1$ genes expression in response to TOP treatment. The expression level of $A B C G 2$ and $A B C B 1$ genes was investigated to determine if TOP treatment can induce their expression in the first days of treatment. In W1 cell line we observed a statistically significant increase in $A B C G 2$ transcript level after $24 \mathrm{~h}$ of treatment $(p<0.05)$. After $48 \mathrm{~h}$ of treatment statistically significant increase was observed only in higher TOP concentration $(p<0.05)$. After $72 \mathrm{~h}$ of treatment $A B C G 2$ transcript level was still upregulated but without statistical significance (Figure 7A). In A2780 and SKOV-3 cell lines we observed concentration and time dependent statistically significant increase in $A B C G 2$ transcript level $(p<0.05, p<0.01$ or $p<0.001)$ (Figure 7B and $\mathrm{C})$. In $\mathrm{W} 1$ cell line we observed concentration-dependent increase in $A B C B 1$ transcript level with maximum increase after $48 \mathrm{~h}$ of treatment $(p<0.05)$ (Figure 8A). In A2780 and SKOV-3 cell lines statistically significant and concentrationdependent increase in $A B C B 1$ mRNA was observed after 24 and $72 \mathrm{~h}$ of treatment $(p<0.05$ in A2780 cell line or $p<0.05$, $p<0.01$ and $p<0.001$ in the SKOV-3 cell line). After $48 \mathrm{~h}$ of treatment in both cell lines we observed lower levels of this transcript in comparison to the same TOP concentration after $24 \mathrm{~h}$ (Figure 8B and C).

Analysis of IFIH1, SAMD4 and EPHA3 genes expression in response to TOP treatment. We did not observe any changes in IFIH1, SAMD4 and EPHA3 genes expression in W1 cell line after TOP treatment (not shown). In A2780 cell line statistically significant increase in IFIHI expression was observed only after $72 \mathrm{~h}$ of treatment $(p<0.05)$ (Figure 9A). In SKOV-3 cell line increased expression of IFIH1 was observed after $24 \mathrm{~h}$ of treatment in both TOP concentration $(p<0.05)$ and after $48 \mathrm{~h}$ in concentration $20 \mathrm{ng} / \mathrm{ml}(p<0.05)$. After $72 \mathrm{~h}$ of treatment IFIH1 mRNA level went down to the level of control (Figure 9B).

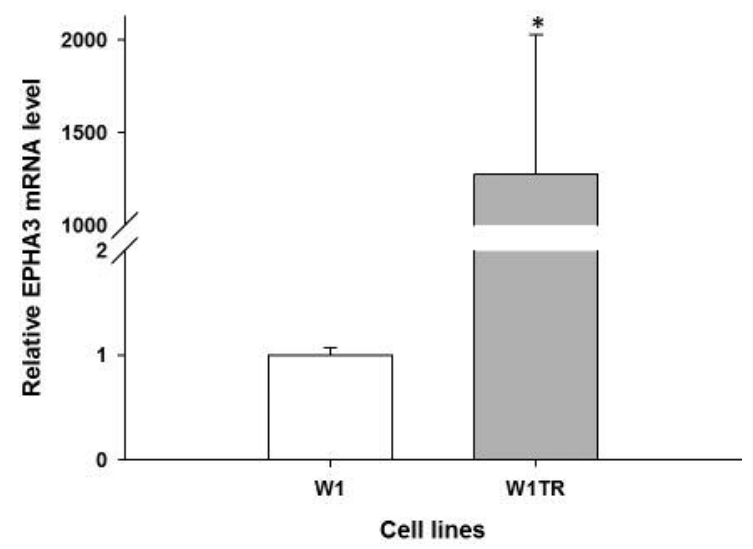

Figure 5. Expression analysis (Q-PCR) of EPHA3 gene in W1 and TOPresistant subline. The Figure presents relative gene expression in resistant cell line (grey bar) with respect to the sensitive cell line (white bar) assigned as 1. Values was considered significant at $* p<0.01$.

A certain decrease in SAMD4 mRNA level was observed after $24 \mathrm{~h}$ of treatment in A2780 cell line $(p<0.05)$. In contrast, an increase in SAMD4 expression was observed in $48 \mathrm{~h}$ after treatment $(p<0.01)$, however $72 \mathrm{~h}$ after treatment transcript level returned to the level similar to control (Figure 10A). In SKOV-3 cell line we observed an up-regulated SAMD4 mRNA level after $24 \mathrm{~h}(p<0.01$ or $p<0.001)$ and $48 \mathrm{~h}(p<0.01)$ of treatment in both TOP concentration. After $72 \mathrm{~h}$ of treatment $S A M D 4$ mRNA was still up-regulated $(p<0.05$ or $p<0.01)$ but at lower level than after $24 \mathrm{~h}$ and $48 \mathrm{~h}$ (Figure 10B).

Analysis of ALDH1Al gene expression after TOP treatment. Different patterns of ALDHIAl expression after TOP treatment were observed in investigated cell lines. In W1 cell line we observed concentration and time dependent statistically significant (with exception of $10 \mathrm{ng} / \mathrm{ml}$ after $24 \mathrm{~h}$ ) increase in ALDH1Al transcript level ( $p<0.05$ or $p<0.01(20 \mathrm{ng} / \mathrm{ml}-72 \mathrm{~h})$ ) (Figure 11A). In the A2780 cell line statistically significant increase of $A L D H 1 A l$ transcript level was observed only after $72 \mathrm{~h}(p<0.05)$ (Figure 11B). In contrast, ALDH1Al transcript level was significantly decreased in SKOV-3 cell line after TOP treatment $(p<0.05, p<0.01$ or $p<0.001)$ (with an exception for $20 \mathrm{ng} / \mathrm{ml}$ after $24 \mathrm{~h}$ ) (Figure 11C). Decrease in ALDH1A1 transcript level was TOP concentration dependent and minimal after $48 \mathrm{~h}$ of treatment.

\section{Discussion}

In the present study we investigated the response to TOP treatment and development of TOP resistance in ovarian cancer cell lines. TOP is one of the drugs used in second line 

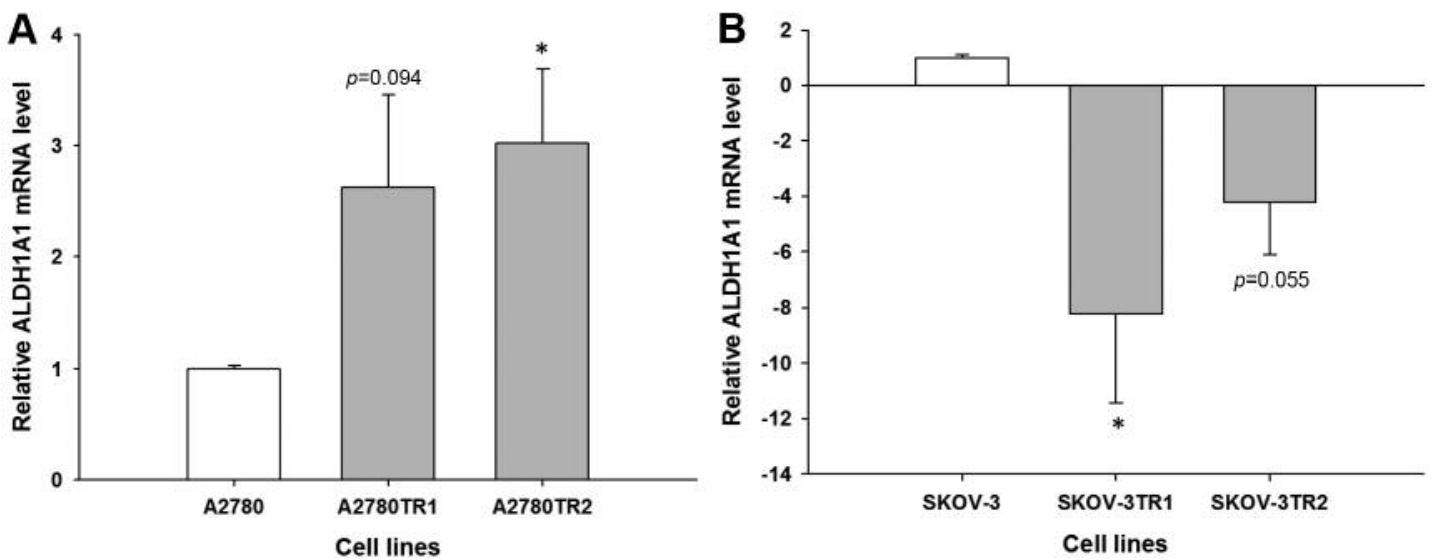

Figure 6. Expression analysis (Q-PCR) of ALDH1A1 gene in A2780 (A), SKOV-3 (B) and TOP-resistant sublines. The Figure presents relative gene expression in resistant cell lines (grey bars) with respect to the sensitive cell line (white bars) assigned as 1 . Values were considered significant at $* p<0.05$.

of ovarian cancer chemotherapy in case of platinum/taxane resistant patients (5-7). In SKOV-3 TOP-resistant cells we observed increased resistance to this drug although at different level. Similar results were observed previously in case of A2780 and W1 TOP-resistance cell lines $(16,18)$. Resistance to TOP is associated mainly with a decreased expression of DNA topoisomerase I (12) or increased expression of drug transporter BCRP encoded by the $A B C G 2$ gene (13-16). We did not observed changes in DNA topoisomerase I expression in any TOP-resistant cell lines (not shown). In contrast, both cell lines showed an increased expression of ABCG2 transcript level. Expression of $B C R P$ has been reported by others in ovarian cancer cell lines exposed to TOP $(13,17)$ as well as in many drug-resistant solid tumors and was associated with mitoxantrone, topotecan, irinotecan, flavopiridol and methotrexate resistance $(14,17)$. Previously we also observed an increased expression of $A B C G 2$ gene in TOP-resistant variants of A2780 $(15,16)$ and $\mathrm{W} 1$ cell lines $(18,39)$. These results indicate that increased expression of $B C R P$ transporter is the main mechanism of TOP resistance in ovarian cancer. However, we observed a big difference of $A B C G 2$ transcript level between TOP-resistance cell lines. In SKOV-3TR1 cell line we observed about 200-fold increase in this transcript level. Even higher increase in $A B C G 2$ mRNA level was observed previously in A2780 and W1 TOP-resistance cell lines (16, 18). In contrast, in SKOV-3TR2 cell line we observed only 7-fold increase in ABCG2 transcript level. Because SKOV3TR2 cell line was more resistant to TOP than SKOV-3TR1 cell line this suggested another additional mechanism responsible for TOP-resistance in this cell line. It has been reported that $\mathrm{P}$-gp expression can also be related to TOPresistance $(40,41)$. This observation was confirmed by our previous studies $(16,18)$. Thus, we checked $A B C B 1$ mRNA level in SKOV-3 and TOP-resistant cell lines. In SKOV-3TR2 cell line we observed increased expression of $A B C B 1$ mRNA. We suggest that the expression of $A B C B 1$ can be an additional mechanism responsible for TOP-resistance in this cell line. Similar observation has been previously made in A2780 TOP-resistance cell lines. In A2780TR2 cell line we observed a lower level of $A B C G 2$ than in A2780TR 1 cell line. This difference was compensated by increased expression of $A B C B 1$ gene in the A2780TR2 cell line (18). Also all PAC-resistance cell lines used in our previous study were cross-resistance to TOP because of P-gp expression (16, 18). In summary, these results further confirm that there exist two mechanisms of TOP-resistance. Classical based on ABCG2/BCRP expression and less common based on ABCB1/P-gp expression.

Our microarray results suggested that other genes can also be increased in TOP-resistance cell lines. In TOP-resistant cell lines derived from W1, A2780 and SKOV-3 cell lines we observed an increased expression of IFIHI gene. This suggests that its expression is specific to TOP-resistant cell lines. So far, IFIHI expression has been described mainly as a cytosolic receptor responsible for double-strand RNA recognition and antiviral response $(29,30)$. Marín-Aguilera et al. reported on decreased expression of IFIHI gene in castration-resistant prostate cancers resistant to Docetaxel (DOC) and in prostate cancer cell lines resistant to DOC (42). In contrast, we observed an up-regulation of this gene in TOP-resistant ovarian cancer cell lines. Thus, the role of IFIH1 in cancer drug resistance can be drug- and cancerdependent. The significance of changes of this gene expression in drug resistance requires further investigation.

Another gene with increased expression in four from five TOP-resistant cell lines was SAMD4 (SMAUG1) encoding a regulatory protein responsible for repression of translation 
A

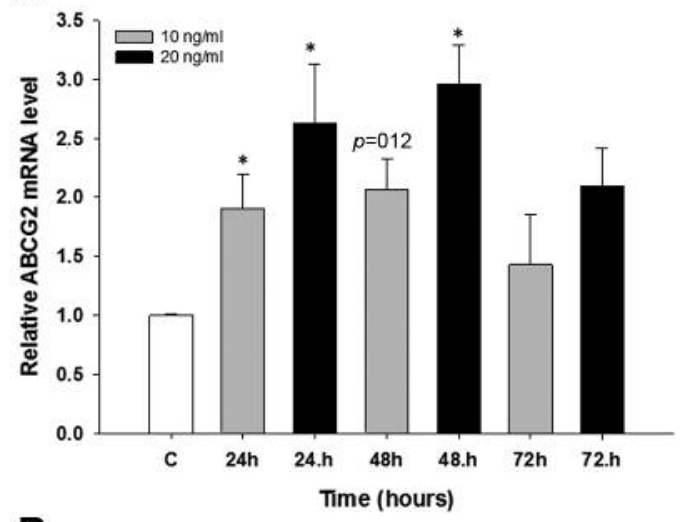

B

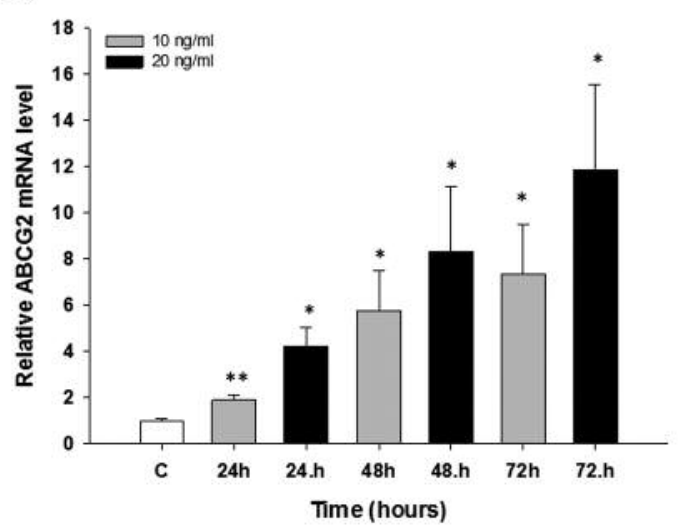

C

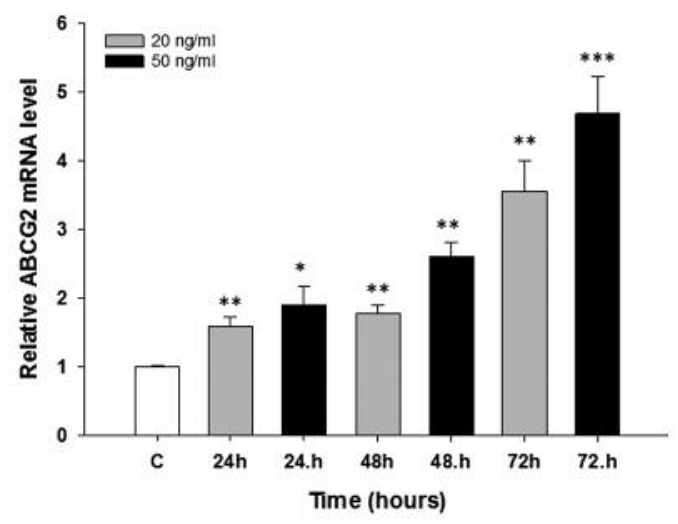

Figure 7. Expression analysis of ABCG2 gene in W1 (A), A2780 (B), $S K O V-3(C)$ ovarian cancer cell lines. The Figure presents relative gene expression in TOP treated cells (grey and black bars) with respect to the untreated control (white bars) assigned as 1 . Values were considered significant at $* p<0.05, * * p<0.01$ and $* * * p<0.001$.

and mRNA decay by binding to SRE elements on target transcripts $(33,34)$. In Drosophila embryo dSMAUG is known to induce the degradation of two-thirds target maternal mRNAs (43). It could be suspected that in stress
A

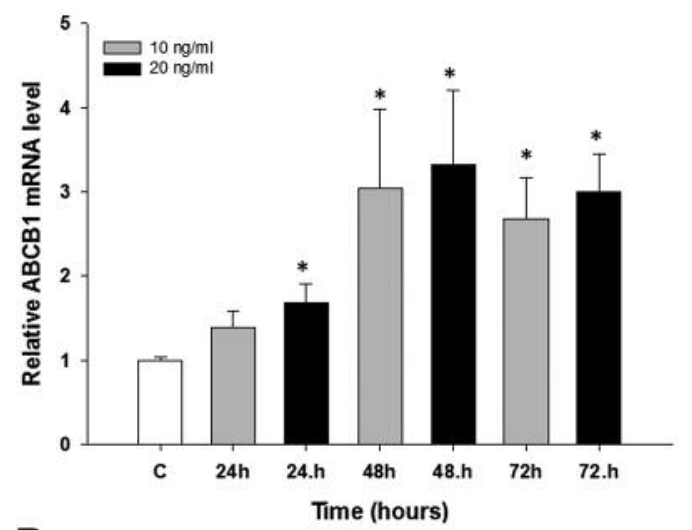

B

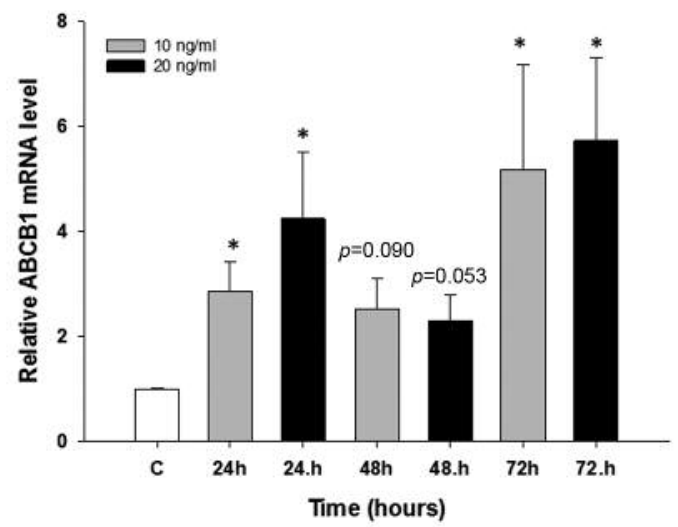

C

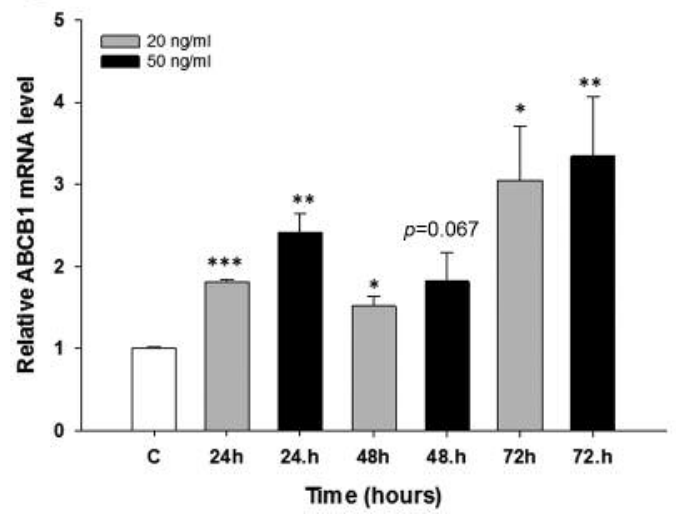

Figure 8. Expression analysis of $A B C B 1$ gene in $W 1(A), A 2780(B)$ and $S K O V-3(C)$ ovarian cancer cell lines. The Figure presents relative gene expression in TOP treated cells (grey and black bars) with respect to the untreated control (white bars) assigned as 1 . Values were considered significant at $* p<0.05, * * p<0.01$ and $* * * p<0.001$.

condition like exposure to cytotoxic agents SAMD4 targets less important transcript leading to inhibition of their translation and/or their degradation. As a result, the cell can focus all attention on expression of genes responsible for 
A

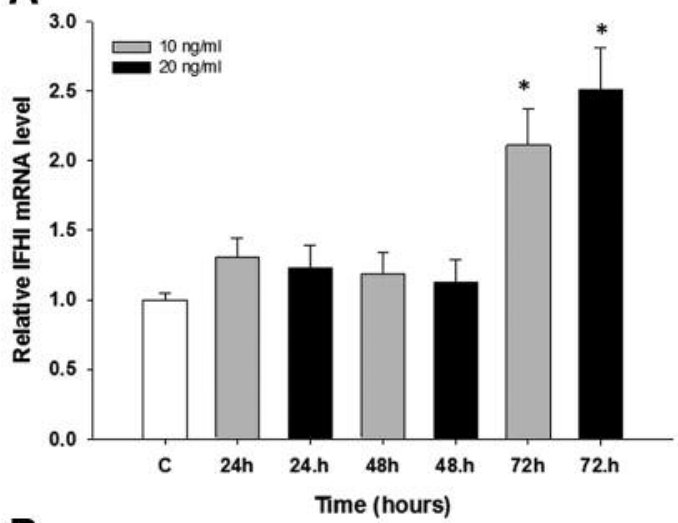

B

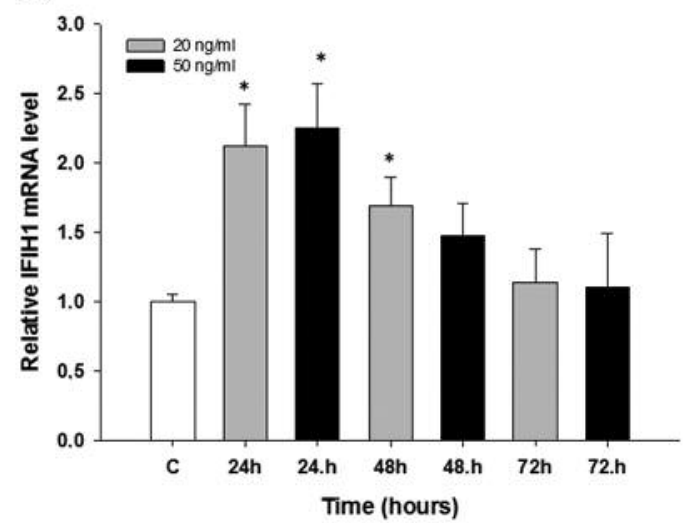

Figure 9. Expression analysis of IFIH1 gene in A2780 (A) and SKOV-3 (B) ovarian cancer cell lines. The Figure presents relative gene expression in TOP treated cells (grey and black bars) with respect to the untreated control (white bars) assigned as 1. Values were considered significant at $* p<0.05$.

protection of the cell against drugs. The best of our knowledge, the expression of this gene in drug resistance or even cancer has not been described so far.

In contrast to abovementioned genes the role of EPHA3 in cancers is well described. Its expression was reported in gastric, prostate, liver and lung cancer among others and usually correlated with tumor progression, poor prognosis and MDR development $(25,26,28)$. EPHA3 belongs to the family of receptor tyrosine kinases (RTKs) and the ligands of this receptors are ephirins. Ligand binding leads to receptor dimerization and auto-phosphorylation. This initiates binding of other signaling molecules and forward signal transduction (44). These signaling pathways regulate and promote cells growth, survival, invasion, motility and MDR development $(28,45)$. In hepatocellular carcinoma EPHA3 expression strongly correlated with metastasis and venous invasion (27). We did not find any report regarding direct role of EPHA3 in drug resistance of cancer or cancer cell lines. In SCLC EPHA3 was involved in development of
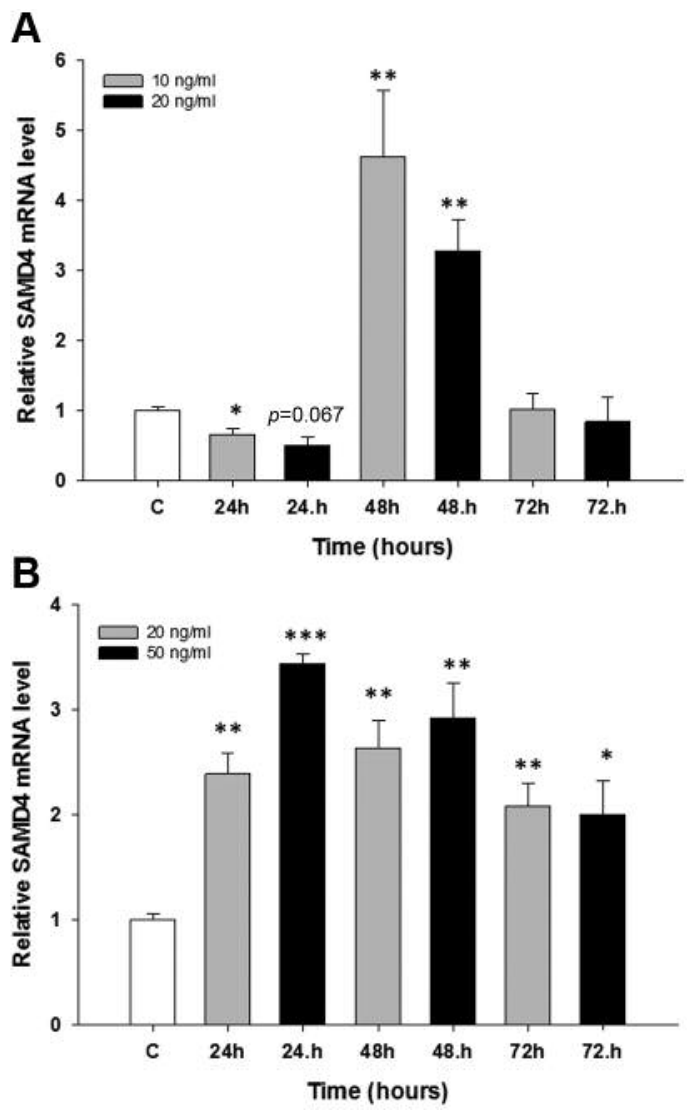

Figure 10. Expression analysis of SAMD4 gene in A2780 (A) and SKOV-3 (B) ovarian cancer cell lines. The Figure presents relative gene expression in TOP treated cells (grey and black bars) with respect to the untreated control (white bars) assigned as 1. The values were considered significant at $* p<0.05, * * p<0.01$ and $* * * p<0.001$.

MDR (28). An increased expression in metastasis can also suggest such a role because metastasis are usually more resistant to chemotherapy than primary tumors. Increased signal transduction in W1TR cell line by EPHA3 receptor can also lead to increased expression of TOP-resistant gene, this however requires further investigation.

According to CSCs theory of drug resistance development in tumors CSCs characterized among others by high expression level of drug transporters like P-gp and BCRP and other cells protecting mechanism are responsible for development of drug resistance (35). The universal marker of CSCs from different solid tumors is expression of ALDH1Al gene (46). In breast cancer the expression of ALDH1A1 correlated with resistance to DOX/PAC based chemotherapy and increased after chemotherapy (47). Increased expression of ALDH1A1 was also reported in cytotoxic drug resistance breast and ovarian cancer cell lines $(37,48)$. Recently, we have reported very high expression level of ALDH1A1 in PAC- and TOP-resistant W1 sublines. These cell lines were 




B
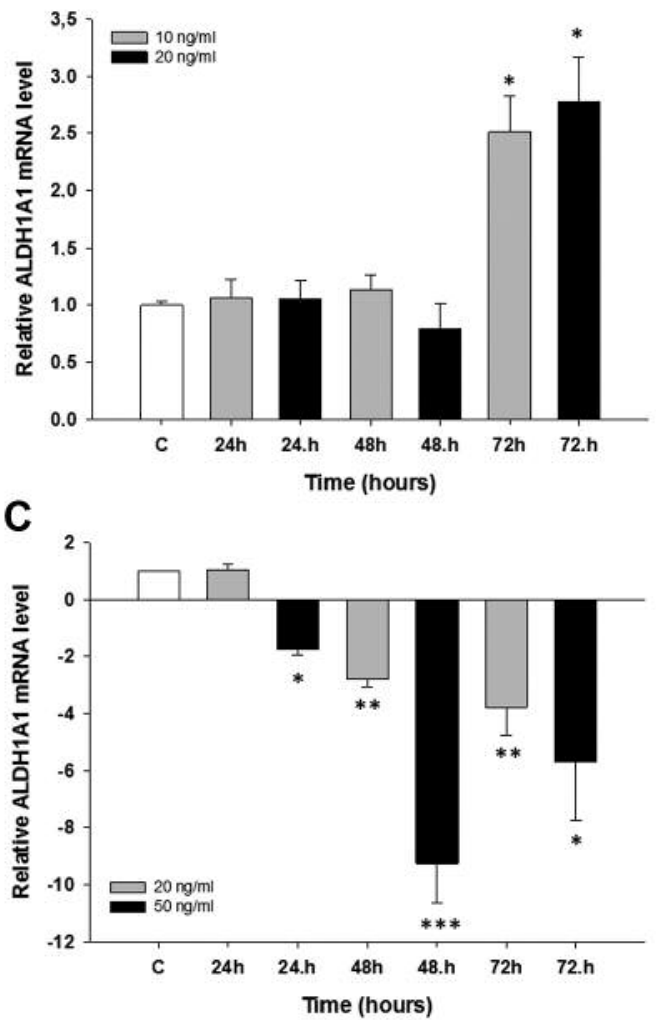

Figure 11. Expression analysis of ALDH1A1 gene in W1 (A), A2780 (B) and SKOV-3 $(C)$ ovarian cancer cell lines. The Figure presents relative gene expression in TOP treated cells (grey and black bars) with respect to the untreated control (white bars) assigned as 1 . The values were considered significant at $* p<0.05, * * p<0.01$ and $* * * p<0.01$.

also characterized by increased expression of P-gp and BCRP, respectively, and have a feature of CSCs (38). Going this way we wanted to check the expression level of ALDHIAl in A2780 and SKOV-3 TOP-resistant sublines, that also express $A B C B 1$ and $A B C G 2$ genes. In A2780 cell line we observed an increase in $A L D H 1 A 1$ mRNA level although this increase was very low. In contrast in SKOV-3 TOP-resistant sublines we observed a down-regulation of $A L D H 1 A 1$ expression. This observation indicates that ALDH1A1, although very often associated with development of MDR, is not an absolute marker of MDR cells. In case of these cell lines development of TOP-resistance can be better explained by a model of acquired resistance (49). Taking into account the complexity and diversity of drug resistance development in cancers, resistance in some cases can be better explained by a model acquired resistance, however in most cases it has feature of both (50).

In the second part of our study we wanted to check if the same genes are expressed after first exposure to TOP at the beginning of TOP-resistance development. In our TOPresistance development models the most important gene in TOP-resistance was $A B C G 2$ and the second most important was $A B C B 1$ so we started analysis from these genes. In A2780 and SKOV-3 cell lines we observed clear concentration and time dependent increase in $A B C G 2$ transcript level that suggests its dominant role in response to TOP after short time exposure. In contrast, in W1 cell line expression of $A B C G 2$ seems to be important after 24 and 48 $\mathrm{h}$ of treatment and less important latter. In this cell line the expression of $A B C B 1$ can play the most important role. In summary, it seems that both drug transporters play an important and complementary role in response to short time TOP-treatment. However, longer exposure to TOP leads to preferential expression of $A B C G 2$ in most cases suggesting that $A B C G 2$ is most important gene in TOP-resistance. Expression of both genes after TOP exposure in sensitive cell lines can be a marker of potential to develop stable TOPresistance.

Although EPHA3 was clearly overexpressed in W1TR cell line, we did not observe any changes in transcript level of this gene after short time exposure to drug. This suggests that EPHA3 plays a role in TOP-resistance only after longtime exposure. Similarly, any changes in IFIHI and SAMD4 were observed in $\mathrm{W} 1$ cell line.

Up-regulated expression of IFIHI seems to be important at the beginning of treatment in SKOV-3 cell line and less important after longer treatment. In contrast, in A2780 cell line $I F I H 1$ mRNA increased only after $72 \mathrm{~h}$, which suggests that other genes are more important after first time contact with TOP in this cell line. Because IFIH1 is not described in context of drug resistance it is difficult to interpret these results.

Maximum level of SAMD4 was observed after 48 hours in A2780 cell line and went down latter. In the SKOV-3 cell line SAMD4 mRNA level was increased in all time points although seemed to go down after $72 \mathrm{~h}$. Because SAMD4 is involved in repression of translation and decay mRNA stability it seems that its expression at the beginning of treatment can lead to elimination of less important transcript in this stress situation and preferential translation of proteins 
involved in TOP-resistance $(33,34)$. This however reacquires further and more detailed study.

According to CSCs theory of drug resistance development small population of cells is resistance to chemotherapy and after exposure to drugs these cells survive (35). Thus, in W1 cell line the up-regulation of $A L D H 1 A 1$ can result not only from increased expression but also from changes of proportion between CSCs and other cells population. This seems to be true because in W1TR cell line a population of ALDH1A1+ cells was observed (38). It could be suspected that ALDH1A1+ population can be present in A2780 cell line, although in A2780 TOP-resistant cell lines the population of ALDH1A1+ cells can be less abundant than in W1TR cell line. It is difficult to explain the significance of the down-regulation of $A L D H 1 A l$ expression after TOPtreatment as well as stable down-regulation of $A L D H 1 A 1$ in TOP-resistance SKOV-3 sublines. To our knowledge this is the first such observation.

\section{Conclusion}

In summary, our results indicate that expression of $A B C G 2$ plays the most important role in TOP-resistance of ovarian cancer cell lines. Expression of $A B C B 1$ seems to play a complementary role in TOP-resistance. Increased expression of SAMD4 can be responsible for preferential translation of TOP-resistant gene in stress condition. The significance of IFIH1 in TOP-resistance requires further investigation. Although important, the expression of EPHA3 seems to be cell line specific. Changes in $A L D H 1 A l$ expression after TOP-treatment are cell like dependent and can be associated with a different model of drug resistance development in investigated cell lines.

\section{Grant support}

This study was supported by grant no. 2014/13/B/NZ5/00334 from the National Science Centre.

\section{References}

1 Garcia M, Jemal A, Ward EM, Center MM, Hao Y, Siegel RL and Thun MJ: Global cancer facts \& figures 2007. Atlanta, American Cancer Society, 2007.

2 Webb PM and Jordan SJ: Epidemiology of epithelial ovarian cancer. Best Pract Res Clin Obstet Gynaecol: 30091-30098, 2016.

3 Hennessy BT, Coleman RL and Markman M: Ovarian cancer. Lancet 374: 1371-1382, 2009.

4 Parmar MK, Ledermann JA, Colombo N, du Bois A, Delaloye JF, Kristensen GB, Wheeler S, Swart AM, Qian W, Torri V, Floriani I, Jayson G, Lamont A, Trope C, Icon and Collaborators AGO: Paclitaxel plus platinum-based chemotherapy versus conventional platinum-based chemotherapy in women with relapsed ovarian cancer: the ICON4/AGO-OVAR-2.2 trial. Lancet 361: 2099-2106, 2003.
5 Webber K and Friedlander M: Chemotherapy for epithelial ovarian, fallopian tube and primary peritoneal cancer. Best Pract Res Clin Obstet Gynaecol: 1-13, 2016.

6 Sehouli J, Stengel D, Oskay-Oezcelik G, Zeimet AG, Sommer H, Klare P, Stauch M, Paulenz A, Camara O, Keil E and Lichtenegger W: Nonplatinum topotecan combinations versus topotecan alone for recurrent ovarian cancer: results of a phase III study of the North-Eastern German Society of Gynecological Oncology Ovarian Cancer Study Group. J Clin Oncol 26: 3176$3182,2008$.

7 Ferrandina G, Ludovisi M, Lorusso D, Pignata S, Breda E, Savarese A, Del Medico P, Scaltriti L, Katsaros D, Priolo D and Scambia G: Phase III trial of gemcitabine compared with pegylated liposomal doxorubicin in progressive or recurrent ovarian cancer. J Clin Oncol 26: 890-896, 2008.

8 Pommier $\mathrm{Y}$, Leo $\mathrm{E}$, Zhang $\mathrm{H}$ and Marchand $\mathrm{C}$ : DNA topoisomerases and their poisoning by anticancer and antibacterial drugs. Chem Biol 17: 421-433, 2010.

9 Wang JC: DNA topoisomerases. Annu Rev Biochem 65: 635692, 1996.

10 Pommier Y, Sun Y, Huang SN and Nitiss JL: Roles of eukaryotic topoisomerases in transcription, replication and genomic stability. Nat Rev Mol Cell Biol 17: 703-721, 2016.

11 Staker BL, Hjerrild K, Feese MD, Behnke CA, Burgin AB Jr. and Stewart L: The mechanism of topoisomerase I poisoning by a camptothecin analog. Proc Natl Acad Sci USA 99: 1538715392, 2002.

12 Rubin EH, Li TK, Duann P and Liu LF: Cellular resistance to topoisomerase poisons. Cancer Treat Res 87: 243-260, 1996.

13 Maliepaard M, van Gastelen MA, de Jong LA, Pluim D, van Waardenburg RC, Ruevekamp-Helmers MC, Floot BG and Schellens JH: Overexpression of the BCRP/MXR/ABCP gene in a topotecan-selected ovarian tumor cell line. Cancer Res 59: 4559-4563, 1999.

14 Robey RW, Polgar O, Deeken J, To KW and Bates SE: ABCG2: determining its relevance in clinical drug resistance. Cancer Metastasis Rev 26: 39-57, 2007.

15 Januchowski R, Zawierucha P, Rucinski M, Andrzejewska M, Wojtowicz K, Nowicki M and Zabel M: Drug transporter expression profiling in chemoresistant variants of the A2780 ovarian cancer cell line. Biomed Pharmacother 68: 447-453, 2014.

16 Januchowski R, Sterzynska K, Zaorska K, Sosinska P, Klejewski A, Brazert M, Nowicki M and Zabel M: Analysis of MDR genes expression and cross-resistance in eight drug resistant ovarian cancer cell lines. J Ovarian Res 9: 65, 2016.

17 Mo L, Pospichalova V, Huang Z, Murphy SK, Payne S, Wang F, Kennedy M, Cianciolo GJ, Bryja V, Pizzo SV and Bachelder RE: Ascites Increases Expression/Function of Multidrug Resistance Proteins in Ovarian Cancer Cells. PLoS One 10: e0131579, 2015.

18 Januchowski R, Wojtowicz K, Sujka-Kordowska P, Andrzejewska M and Zabel M: MDR gene expression analysis of six drug-resistant ovarian cancer cell lines. Biomed Res Int 2013: 241763, 2013.

19 Januchowski R, Zawierucha P, Rucinski $\mathrm{M}$ and Zabel M: Microarray-based detection and expression analysis of extracellular matrix proteins in drugresistant ovarian cancer cell lines. Oncol Rep 32: 1981-1990, 2014. 
20 Januchowski R, Swierczewska M, Sterzynska K, Wojtowicz K, Nowicki $M$ and Zabel M: Increased Expression of Several Collagen Genes is Associated with Drug Resistance in Ovarian Cancer Cell Lines. J Cancer 7: 1295-1310, 2016.

21 Himanen JP and Nikolov DB: Eph receptors and ephrins. Int J Biochem Cell Biol 35: 130-134, 2003.

22 Taylor H, Campbell J and Nobes CD: Ephs and ephrins. Curr Biol 27: R90-R95, 2017.

23 Surawska H, Ma PC and Salgia R: The role of ephrins and Eph receptors in cancer. Cytokine Growth Factor Rev 15: 419-433, 2004.

24 Heroult M, Schaffner F and Augustin HG: Eph receptor and ephrin ligand-mediated interactions during angiogenesis and tumor progression. Exp Cell Res 312: 642-650, 2006.

$25 \mathrm{Xi} \mathrm{HQ}, \mathrm{Wu}$ XS, Wei B and Chen L: Aberrant expression of EphA3 in gastric carcinoma: correlation with tumor angiogenesis and survival. J Gastroenterol 47: 785-794, 2012.

$26 \mathrm{Xi} \mathrm{HQ}$ and Zhao P: Clinicopathological significance and prognostic value of EphA3 and CD133 expression in colorectal carcinoma. J Clin Pathol 64: 498-503, 2011.

27 Lu CY, Yang ZX, Zhou L, Huang ZZ, Zhang HT, Li J, Tao KS and Xie BZ: High levels of EphA3 expression are associated with high invasive capacity and poor overall survival in hepatocellular carcinoma. Oncol Rep 30: 2179-2186, 2013.

28 Peng J, Wang Q, Liu H, Ye M, Wu X and Guo L: EPHA3 regulates the multidrug resistance of small cell lung cancer via the PI3K/BMX/STAT3 signaling pathway. Tumour Biol 37: 11959-11971, 2016.

29 Kato H, Takeuchi O, Sato S, Yoneyama M, Yamamoto M, Matsui K, Uematsu S, Jung A, Kawai T, Ishii KJ, Yamaguchi O, Otsu K, Tsujimura T, Koh CS, Reis e Sousa C, Matsuura Y, Fujita $\mathrm{T}$ and Akira S: Differential roles of MDA5 and RIG-I helicases in the recognition of RNA viruses. Nature 441: 101$105,2006$.

30 Takeuchi O and Akira S: MDA5/RIG-I and virus recognition. Curr Opin Immunol 20: 17-22, 2008

31 Kovacsovics M, Martinon F, Micheau O, Bodmer JL, Hofmann $\mathrm{K}$ and Tschopp J: Overexpression of Helicard, a CARDcontaining helicase cleaved during apoptosis, accelerates DNA degradation. Curr Biol 12: 838-843, 2002.

32 Lin L, Su Z, Lebedeva IV, Gupta P, Boukerche H, Rai T, Barber GN, Dent P, Sarkar D and Fisher PB: Activation of Ras/Raf protects cells from melanoma differentiation-associated gene-5induced apoptosis. Cell Death Differ 13: 1982-1993, 2006.

33 Pinder BD and Smibert CA: Smaug: an unexpected journey into the mechanisms of post-transcriptional regulation. Fly (Austin) 7: 142-145, 2013.

34 Aviv T, Lin Z, Lau S, Rendl LM, Sicheri F and Smibert CA: The RNA-binding SAM domain of Smaug defines a new family of post-transcriptional regulators. Nat Struct Biol 10: 614-621, 2003.

35 Januchowski R, Wojtowicz $\mathrm{K}$ and Zabel M: The role of aldehyde dehydrogenase (ALDH) in cancer drug resistance. Biomed Pharmacother 67: 669-680, 2013.

36 Wang YC, Yo YT, Lee HY, Liao YP, Chao TK, Su PH and Lai HC: ALDH1-bright epithelial ovarian cancer cells are associated with CD44 expression, drug resistance, and poor clinical outcome. Am J Pathol 180: 1159-1169, 2012.
37 Landen CN Jr., Goodman B, Katre AA, Steg AD, Nick AM, Stone RL, Miller LD, Mejia PV, Jennings NB, Gershenson DM, Bast RC, Jr., Coleman RL, Lopez-Berestein G and Sood AK: Targeting aldehyde dehydrogenase cancer stem cells in ovarian cancer. Mol Cancer Ther 9: 3186-3199, 2010.

38 Januchowski R, Wojtowicz K, Sterzynska K, Sosinska P, Andrzejewska M, Zawierucha $\mathrm{P}$, Nowicki $\mathrm{M}$ and Zabel $\mathrm{M}$ : Inhibition of ALDH1A1 activity decreases expression of drug transporters and reduces chemotherapy resistance in ovarian cancer cell lines. Int J Biochem Cell Biol 78: 248-259, 2016.

39 Januchowski R, Zawierucha P, Andrzejewska M, Rucinski M and Zabel $\mathrm{M}$ : Microarray-based detection and expression analysis of ABC and SLC transporters in drug-resistant ovarian cancer cell lines. Biomed Pharmacother 67: 240-245, 2013.

40 Ozben T: Mechanisms and strategies to overcome multiple drug resistance in cancer. FEBS Lett 580: 2903-2909, 2006.

41 Vanhoefer U, Muller MR, Hilger RA, Lindtner B, Klaassen U, Schleucher N, Rustum YM, Seeber S and Harstrick A: Reversal of MDR1-associated resistance to topotecan by PAK-200S, a new dihydropyridine analogue, in human cancer cell lines. Br J Cancer 81: 1304-1310, 1999.

42 Marin-Aguilera M, Codony-Servat J, Kalko SG, Fernandez PL, Bermudo R, Buxo E, Ribal MJ, Gascon P and Mellado B: Identification of docetaxel resistance genes in castration-resistant prostate cancer. Mol Cancer Ther 11: 329-339, 2012.

43 Tadros W, Goldman AL, Babak T, Menzies F, Vardy L, OrrWeaver T, Hughes TR, Westwood JT, Smibert CA and Lipshitz HD: SMAUG is a major regulator of maternal mRNA destabilization in Drosophila and its translation is activated by the PAN GU kinase. Dev Cell 12: 143-155, 2007.

44 Castano J, Davalos V, Schwartz S Jr. and Arango D: EPH receptors in cancer. Histol Histopathol 23: 1011-1023, 2008.

45 Blume-Jensen $\mathrm{P}$ and Hunter T: Oncogenic kinase signalling. Nature 411: 355-365, 2001.

$46 \mathrm{Ma}$ I and Allan AL: The role of human aldehyde dehydrogenase in normal and cancer stem cells. Stem Cell Rev 7: 292-306, 2011.

47 Tanei T, Morimoto K, Shimazu K, Kim SJ, Tanji Y, Taguchi T, Tamaki Y and Noguchi S: Association of breast cancer stem cells identified by aldehyde dehydrogenase 1 expression with resistance to sequential Paclitaxel and epirubicin-based chemotherapy for breast cancers. Clin Cancer Res 15: 4234-4241, 2009.

48 Croker AK and Allan AL: Inhibition of aldehyde dehydrogenase (ALDH) activity reduces chemotherapy and radiation resistance of stem-like ALDHhiCD44(+) human breast cancer cells. Breast Cancer Res Treat 133: 75-87, 2012.

49 Greaves M and Maley CC: Clonal evolution in cancer. Nature 481: 306-313, 2012.

50 Shackleton M, Quintana E, Fearon ER and Morrison SJ: Heterogeneity in cancer: cancer stem cells versus clonal evolution. Cell 138: 822-829, 2009.

Received February 22, 2017

Revised March 14, 2017

Accepted March 15, 2017 